\title{
HYDROGEN EVOLUTION AND DISSOLUTION ON GRAPHITE ELECTRODES IN MOLTEN POTASSIUM BISULPHATE-II. KINETICS AND MECHANISM OF THE REACTIONS ON POROUS GRAPHITE*
}

\author{
E. J. Balskus, W. E. Triaca and A. J. Arvía \\ División Electroquímica, Instituto Superior de Investigaciones, Facultad de Ciencias Exactas, \\ Universidad Nacional de La Plata, La Plata, Argentina
}

\begin{abstract}
The electrochemical evolution and dissolution of hydrogen in potassium bisulphate melt have been studied on porous graphite electrodes in the temperature range from $245-280^{\circ} \mathrm{C}$. Kinetic parameters were obtained in the conventional way both for steady as well as non-steady conditions and are compared to those previously derived for dense graphite electrodes.

The cathodic and anodic reactions are not straightforwardly complementary processes. The former is explained in terms of a conventional reaction mechanism for the hydrogen electrode involving either a hydrogen adatom combination reaction or a hydrogen ion plus adatom reaction as rate-determining. The anodic reaction is interpreted in terms of various possible mechanisms comprising a one-half order rate equation with respect to the hydrogen gas pressure. The most likely mechanism comprises a competition between the ionization of hydrogen adatoms and the oxidation of graphite at active sites located at the surface. Thermal effects are in agreement with the postulated reaction mechanisms.
\end{abstract}

Résumé-On a étudié le dégagement et la dissolution électrochimique de l'hydrogène dans le bisulphate de potassium fondu sur des électrodes de graphite poreuses à des témperatures de $245-280^{\circ} \mathrm{C}$. Les paramètres cinétiques furent obtenus comme d'habitude pour les conditions autant stationnaires que non-stationnaires et sont comparés avec les paramètres derivés pour des électrodes de graphite dense.

Les réactions anodiques et cathodiques ne sont pas directement des procès complémentaires. La prémière est expliquée par un mecanisme de réaction conventionnel pour l'électrode d'hydrogène comprenant autant la réaction de récombination des adatomes d'hydrogène que la réaction de l'ion hydrogène plus des adatomes. La réaction anodique est interpretée par divers mécanismes possibles comprenant une équation de velocité de demi-ordre en relation avec la pression du gas d'hydrogène. Le mécanisme plus probable comprend une compétence entre l'ionisation des adatomes d'hydrogène et l'oxidation des points actifs localisés sur la surface du graphite. Des effets thermiques concordent avec les mécanismes de réaction postulés.

Zusammenfassung-Es wurde die Entwicklung und Lösung von Wasserstoff in geschmolzenem Kaliumbisulfat an porösen Grafitelektroden im Temperaturbereich zwischen 245 und $280^{\circ} \mathrm{C}$ untersucht. Die kinetischen Parameter für stationäre und nichtstationäre Bedingungen wurden in der üblichen Weise bestimmt und mit den früher an dichten Grafitelektroden abgeleiteten verglichen.

Die kathodischen und anodischen Reaktionen sind keinc absolut komplementäre Prozesse. Erstere kann mit einem konventionellen Reaktionsmechanismus für die Wasserstoff-Elektrode erklärt werden, mit entweder einer Rekombination von adsorbierten Wasserstoffatomen oder einer Reaktion von Wasserstoff-Ion und adsorbiertem Atom als geschwindigkeitsbestimmendem Schritt. Die anodische Reaktion wird mit dem Vorliegen verschiedener möglicher Mechanismen interpretiert, die eine Reaktion halber Ordnung in Bezug auf den Wasserstoffgasdruck enthalten. Die wahrscheinlichste Reaktion wird eine Konkurrenzreaktion zwischen der Ionisierung von adsorbierten Wasserstoffatomen und einer Oxydation von Grafit an den aktiven Stellen der Grafitoberfläche darstellen. Thermische Effekte stehen in Uebereinstimmung mit den vorgeschlagenen Reaktionsmechanismen.

\section{INTRODUCTION}

A GREAT deal of work on the electrochemical oxidation of hydrogen refers to the reaction occurring on platinum electrodes in aqueous solutions. Several papers ${ }^{1-7}$ give most of the bibliography on the topic. From these studies, it was concluded that the reaction can occur in four different ways, the most important being the electrochemical oxidation of the surface to attain a surface particularly active for hydrogen

* Manuscript received 29 July 1970. 
oxidation. However, from the study of this reaction under conditions of extreme purity, no definite quantitative conclusions could be drawn, probably because of the lack of reasonable quantitative information about competitive adsorption of hydrogen and different anions in the presence of dipolar molecules of the solvent.

In contrast to the study of the electrochemical oxidation of hydrogen on platinum in aqueous media, there are only few studies of the reaction on graphite electrodes. The study of the dissolution of hydrogen adsorbed on catalysed carbon electrodes gave a linear relationship between electrode potential and degree of surface coverage by hydrogen adatoms and it also indicated that the presence of the electrolyte at the interface enormously increased the amount of hydrogen which can be adsorbed on the electrode. ${ }^{8}$

The study of the hydrogen-electrode reactions on dense graphite in molten bisulphate, described in part $I, 9$ gave interesting information on both the cathodic and the anodic reactions. However, those results were rather ambiguous as far as any possible contribution of mass-transport processes in the electrode reactions. To clear up this point, it was reasonable to attempt the study of the same electrochemical processes by using graphite electrodes of the porous type.

The kinetic parameters obtained for the hydrogen electrode on dense graphite in molten bisulphate, previously reported,, 90 have been confirmed for the porous electrode. Consequently, the interpretation of the results in terms of the more likely reaction pathways has been in principle feasible. It is probable that the reactions occurring during the anodic oxidation of hydrogen gas in molten potassium bisulphate take place in two stages, comprising initially the adsorption of hydrogen on the graphite and subsequently the electrochemical ionization of the adsorbed gas to form either hydrogen ions in the melt, or water if the oxidized surface participates in the electrode process.

\section{EXPERIMENTAL TECHNIQUE}

The scheme of the electrolysis cell and of the porous graphite electrode are shown in Figs. 1 and 2. The porous electrode was mounted on a dense graphite rod of $2 \mathrm{~cm}$ diameter and $15 \mathrm{~cm}$ long, supported from the upper part of the cell by means of a standard female ground joint. The extreme of the graphite rod, ending as a truncated cone, was made of a porous graphite disk FC-11 (Pure Carbon Co.) of variable thickness. The graphite rod was axially perforated to allow gases to be in contact with the electrolyte through the porous graphite disk. A small gas chamber was left between the end of the axial duct and the porous disk, so as to have a uniform accessibility of the gas through the porous disk. Most of the experiments were performed with porous graphite disks of $6 \mathrm{~mm}$ thickness although 2-mm and 4-mm disks were occasionally employed. Once the whole electrode was assembled, the following pre-treatment was done $^{11}$ (i) boiled in concentrated hydrochloric acid (AR) for $20 \mathrm{~min}$; (ii) boiled and rinsed in distilled water 3 or 4 times for about $30 \mathrm{~min}$; (iii) dried in an air oven at $120^{\circ} \mathrm{C}$ for about $30 \mathrm{~min}$ and (iv) finally desiccated in a vacuum oven at $240^{\circ} \mathrm{C}$ for 12 to $15 \mathrm{~h}$ period. The working electrode was covered with boron nitride paint as in the case of dense graphite, ${ }^{9.10}$ except for the porous disk, which acted as the only electrochemically active surface.

The counter-electrode and reference electrode as well as the electrolyte and its preparation have been described. ${ }^{12.13}$ The hydrogen/nitrogen gas mixtures were obtained from cylinders containing high purity gases, specially prepared for the purpose 


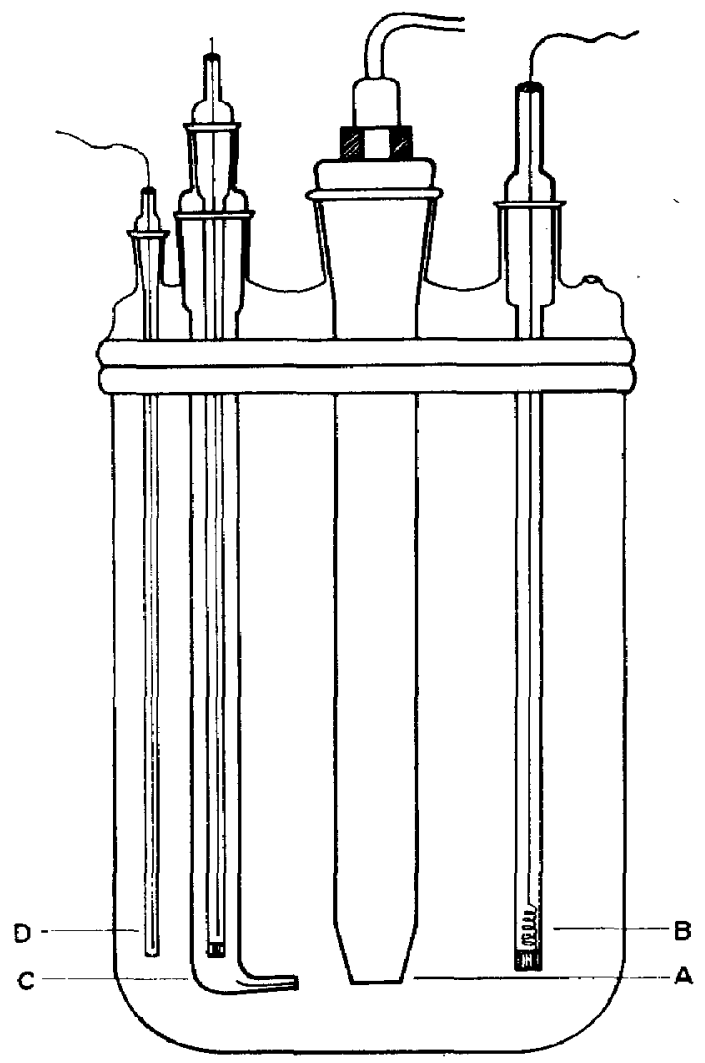

FIG. 1. Scheme of the electrolysis cell.

A, working electrode; $\mathbf{B}$, counter-electrode; $C$, reference electrode; $\mathbf{D}$, thermocouple.
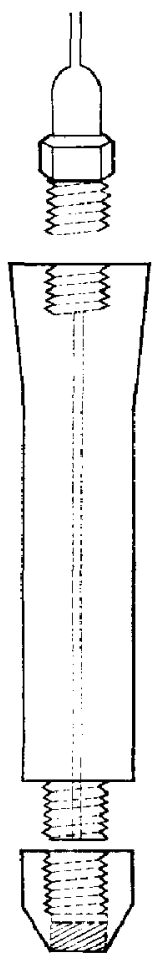

FIG. 2. Detail of the porous graphite working electrode. 
(La Oxígena S.A.). The composition of the gas mixtures was evaluated by gas chromatography.

The electrochemical techniques already mentioned for experiments with dense graphite electrodes were used in the present experiments. However, special attention was paid to potentiostatic measurements. The experimental conditions covered by the experiments were nearly the same as those described in part $I_{.}{ }^{9}$

To determine the extent of the melt wetting on the graphite surface, the evaluation of contact angles at the hydrogen/melt/graphite interface was attempted. For the purpose, a small amount of salt was melted on a flat graphite plate under a hydrogen gas pressure. The graphite plate was located inside a heated tube ended in two parallel flat glass windows. The arrangement was mounted on an optical bench and was properly illuminated to take pictures of the molten sample at any time.

\section{RESULTS}

\section{Steady galvanostatic cathodic $\mathrm{E} / \mathrm{i}$ curves}

These runs were made under continuous saturation of the melt with hydrogen gas at $1 \mathrm{~atm}$ pressure. As described in part $1,{ }^{9}$ a cathodic pulse of $1 \mathrm{~mA}$ and $10 \mathrm{~min}$ duration was applied to the working electrode to achieve uniform surface conditions for the experiments. Very reproducible cathodic $E / i$ curves were obtained in these runs. The $E / \log i$ plots, as shown in Fig. 3, exhibit three well-defined regions. In the

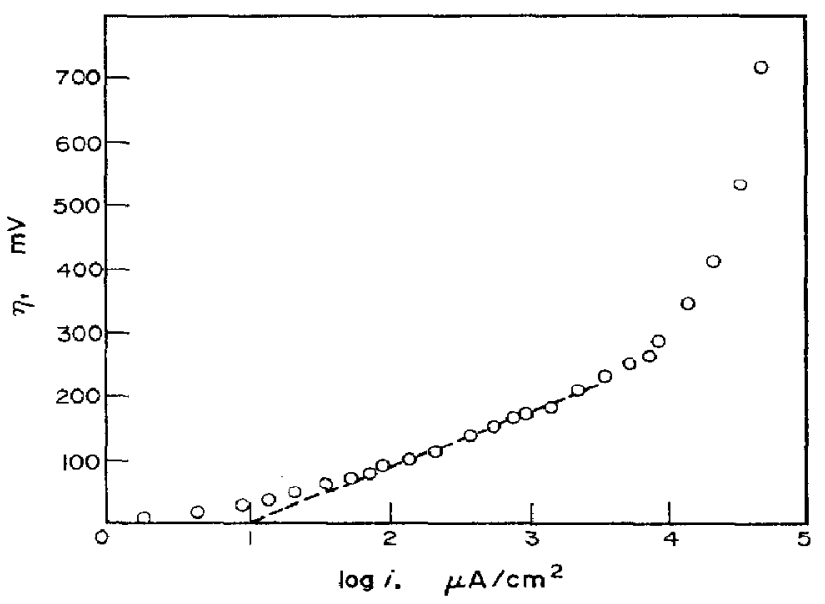

FIG. 3. Galvanostatic cathodic $\eta / \log i$ plot at $245^{\circ} \mathrm{C}$.

$\log i$ range from 1.6 to 4.0 a reasonable good Tafel line appears, involving a slope, $\left(b_{\mathrm{T}}\right)_{\mathrm{o}}$, which is of the order of $2 \cdot 3 R T / F$ V. At lower cds, the $E / \log i$ plot bends up as compared to the Tafel line of slope $2 \cdot 3 R T / F$, the same occurring at the highest cds, where a limiting current is approached. The Tafel slopes and the exchange current densities $i_{0}$ obtained at different temperatures from these $E / \log i$ plots are assembled in Table 1. The $i_{0}$ values increase with temperature, and from the Arrhenius plot shown in Fig. 4, the experimental activation energy derived for the cathodic reaction is $\left(\Delta H^{*}\right)_{\mathrm{o}}=11 \pm 1 \mathrm{kcal} / \mathrm{mole}$. This figure is remarkably lower than the one reported for dense graphite electrodes. ${ }^{9,10}$ 
Table 1. Kinetic Parameters derived from cathodic tafel LINES

\begin{tabular}{cccc}
\hline $\begin{array}{c}\text { Temp } \\
{ }^{\circ} \mathrm{C}\end{array}$ & $\begin{array}{c}2 \cdot 3(R T / F \\
\mathrm{V}\end{array}$ & $\begin{array}{c}\left(b_{\mathrm{T}}\right)_{\mathrm{c}} \\
\mathrm{V}\end{array}$ & $\begin{array}{c}i_{\mathrm{o}} \\
\mu \mathrm{A} / \mathrm{cm}^{2}\end{array}$ \\
\hline 245 & $0 \cdot 103$ & $0 \cdot 095$ & $10 \cdot 0$ \\
264 & $0 \cdot 107$ & $0 \cdot 098$ & $15 \cdot 1$ \\
289 & $0 \cdot 112$ & $0 \cdot 110$ & $25 \cdot 1$ \\
\hline
\end{tabular}

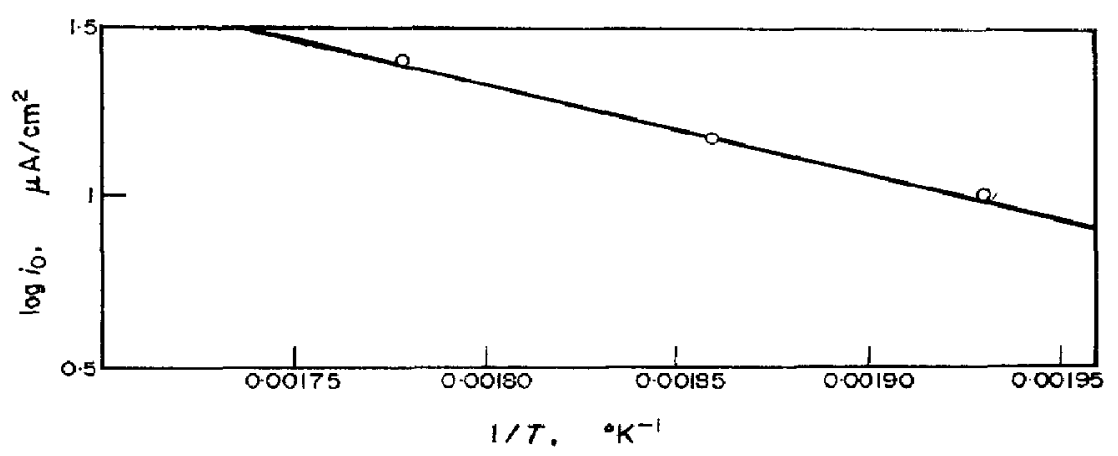

FIg. 4. Arrhenius plot. Cathodic runs.

\section{Potentiostatic cathodic E/i curves}

The potentiostatic cathodic runs were made under the same conditions already indicated for the galvanostatic runs. A typical curve is shown in Fig. 5. The kinetic parameters agree with those already reported in Table 1. Another set of experiments was also made consisting in first polarizing a fresh working electrode a few $\mathrm{mV}(<50$ $\mathrm{mV}$ ) from the rest potential towards cathodic overvoltages, then retracing the curve

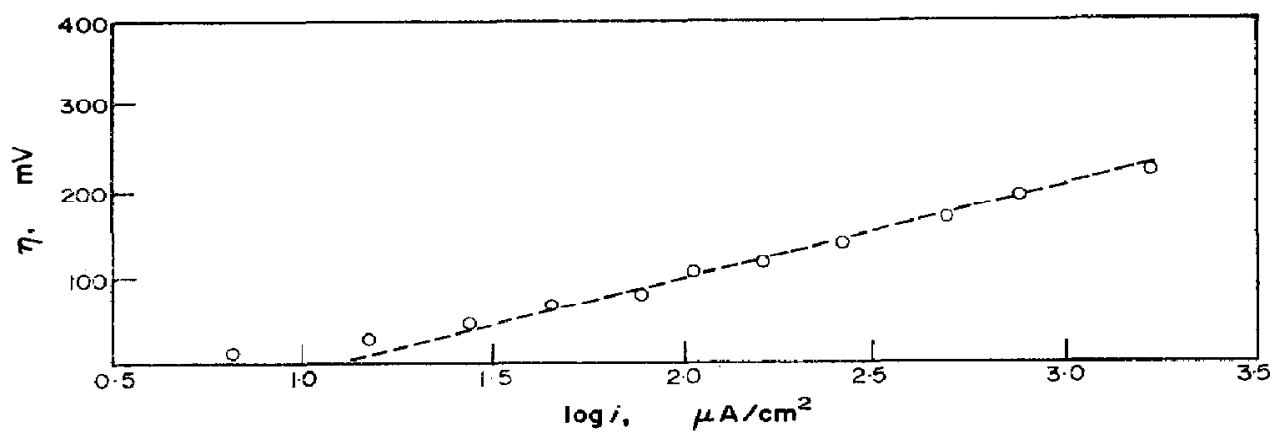

FIG. 5. Potentiostatic cathodic $\eta / \log i$ plot at $245^{\circ} \mathrm{C}$.

until about the same anodic overvoltage was reached, and finally again at the rest potential by decreasing the anodic polarization, to complete a polarization cycle. Results of these experiments are depicted in Fig. 6. It was deduced from this that no hysteresis loop exists in the cathodic region but a net hysteresis occurs in the anodic potential region. These results receive further comment in the Discussion. The stoichiometric number, $y$, for the cathodic reaction, derived from the linear $E / i$ polarization curve, at low cathodic overvoltage was equal to $1 \cdot 2 \pm 0.2$. 


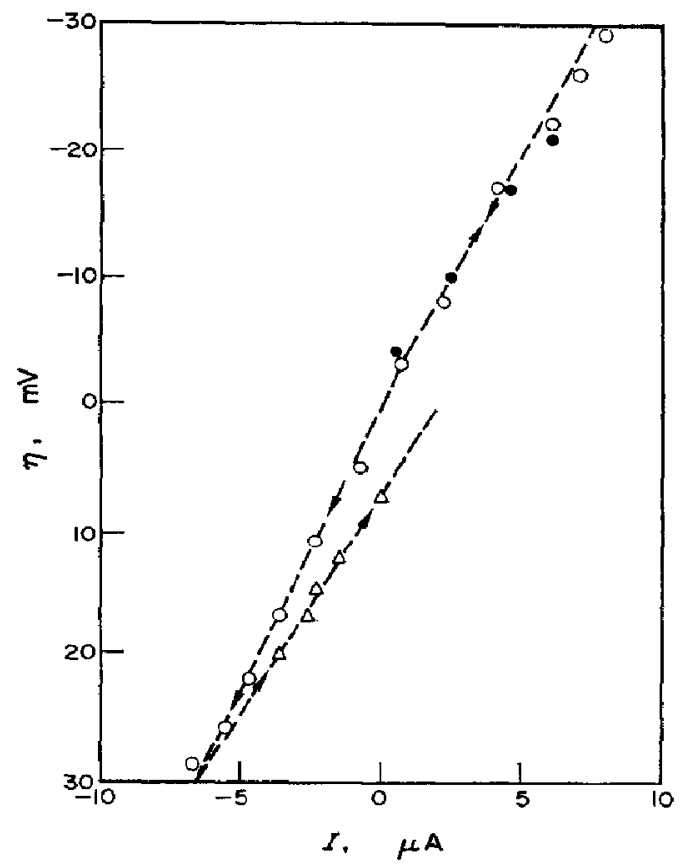

FIG. 6. $\eta / I$ plot at low overpotentials. Temperature: $267^{\circ} \mathrm{C}$. $\varphi$, upward polarization; $O$, downward polarization; $\Delta$, cycling polarization.

\section{Cathodic non-steady measurements}

Typical semilogarithmic plots of cathodic overvoltage decay are shown in Figs. 7 and 8. They exhibit the already known features of overvoltage decay characterizing activated electrode processes. The decay slopes, $\left(b_{\mathbf{a}}\right)_{0}$, cover about two $\log$ (time) units

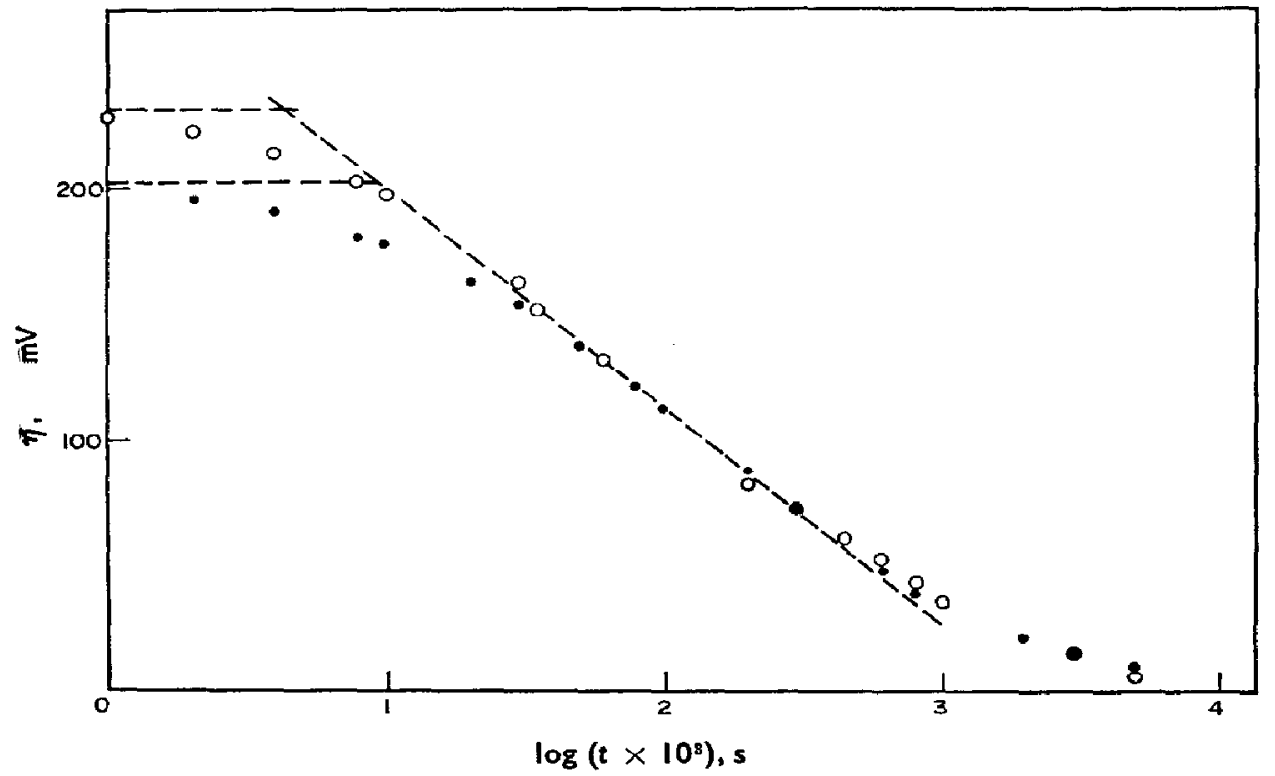

Fig. 7. Typical cathodic decay curves at $245^{\circ} \mathrm{C}$.

$\mathrm{Cd}$ at interruption:, $885 \times 10^{-6} ; 0,1770 \times 10^{-6} \mathrm{~A} / \mathrm{cm}^{2}$. Dashed point intersections indicate $t^{\prime}$ values. 


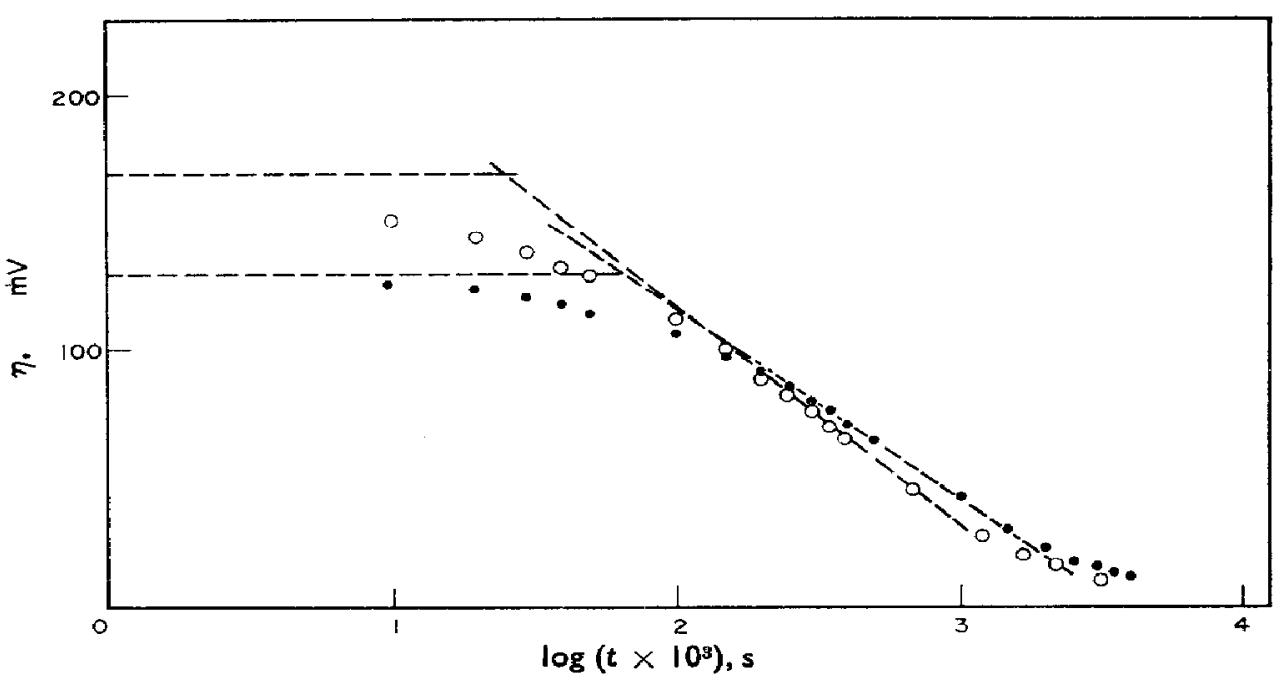

Fig. 8. Typical cathodic decay curves at $245^{\circ} \mathrm{C}$.

Cd at interruption: $\bullet, 142 \times 10^{-1} ; 0,354 \times 10^{-6} \mathrm{~A} / \mathrm{cm}^{2}$. Dashed point intersections indicate $t^{\prime}$ values.

TABle 2. Kinetic Data obtained From emf Decay CuRVes

\begin{tabular}{cccccc}
\hline $\begin{array}{c}\text { Temp } \\
{ }^{C}\end{array}$ & $\mu \mathrm{A} / \mathrm{cm}^{2}$ & $\stackrel{i}{\mathrm{~V}}$ & $\begin{array}{c}2.3(R T / F) \\
\mathrm{V}\end{array}$ & $\begin{array}{c}\left(b_{\mathrm{d}}\right)_{\mathrm{c}} \\
\mathrm{V}\end{array}$ & $\begin{array}{c}C_{\mathrm{e}} \\
\mu \mathrm{F} / \mathbf{c m}^{2}\end{array}$ \\
\hline 245 & 142 & 0.156 & 0.103 & 0.075 & 292 \\
& 354 & 0.183 & 0.103 & 0.087 & 236 \\
& 885 & 0.216 & 0.103 & 0.088 & 210 \\
& 1770 & 0.246 & 0.103 & 0.088 & 199 \\
& 708 & 0.128 & 0.109 & 0.068 & 496 \\
& 1328 & 0.150 & 0.109 & 0.082 & 314 \\
& 2480 & 0.175 & 0.109 & 0.084 & 253 \\
\hline
\end{tabular}

and their values are slightly lower than $2 \cdot 3(R T / F) \mathrm{V}$. Kinetic parameters derived from these curves are assembled in Table 2, including the apparent electrode differential capacitances, $C_{e}$, at the overvoltage of current interruption. Apparent electrode differential capacitances of the graphite electrode obtained from the galvanostatic build-up of cathodic overvoltage are of the order of $350 \mu \mathrm{F} / \mathrm{cm}^{2}$.

\section{Anodic galvanostatic $\mathrm{E} / \mathrm{i}$ curves}

After an abortive attempt to perform the anodic experiments under a pressure just enough to avoid the porous electrode overflooding, experiments were run under net gas bubbling. In this way the tendency of the porous electrode to clog was eliminated. Two simultaneous effects caused the above-mentioned drawback: oxidation of the electrode surface, and pyrosulphate formation on the electrode surface.

A set of anodic $E / i$ curves is shown in Fig. 9. One observes a neat anodic limiting cd which satisfies reasonably well a square-root dependence on the hydrogen gas pressure already found for densc graphite electrodes. These results are shown in 


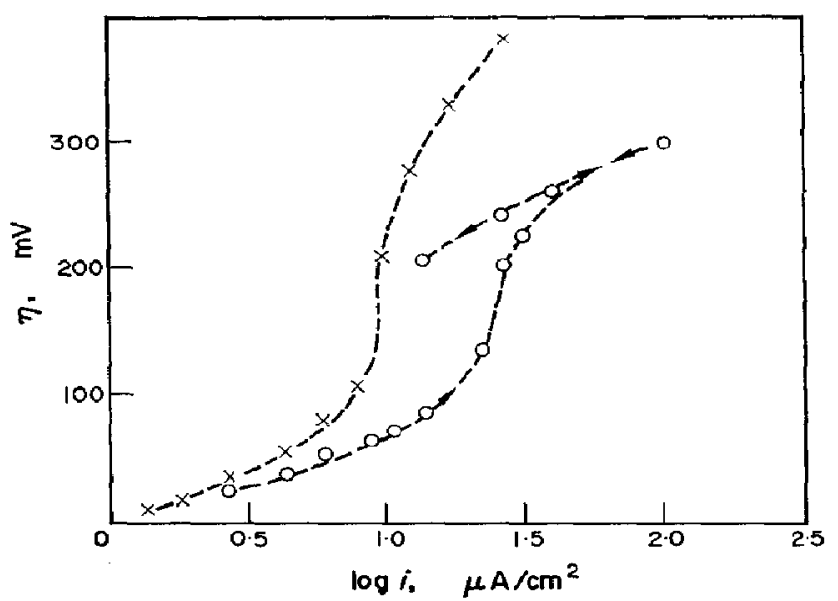

Fra. 9. Galvanostatic anodic $\eta / \log i$ plot at $255^{\circ} \mathrm{C}$ under different hydrogen partial pressures.

$0,1.0 ; \times, 0 \cdot 1 \mathrm{~atm} \mathrm{H}$.

Fig. 10. The observed limiting cds are not affected by changes of the hydrogen gas flow rate. It should be stressed, however, that the only way of getting a reproducible anodic limiting cd was by running galvanostatic experiments with increasing anodic polarization. A reverse procedure, that is to retrace the $E / i$ curve backwards from anodic overvoltages exceeding those corresponding to the anodic limiting $\mathrm{cd}$, yielded a hysteresis, as seen in Fig. 9, and under these circumstances, the anodic limiting od was no longer observed. In principle, this behaviour would suggest a drastic change of the electrode surface after reaching the high positive potentials. These results should also be compared to the anodic hysteresis previously mentioned after cycling cathodic and anodic overvoltages in the vicinity of the rest potential.

No kinetic influence of the hydrogen-gas diffusion through the free electrolyte part of the porous electrode on the electrochemical process was detected, as deduced from data assembled in Table 3 , which reports experiments with porous electrodes of different thickness.

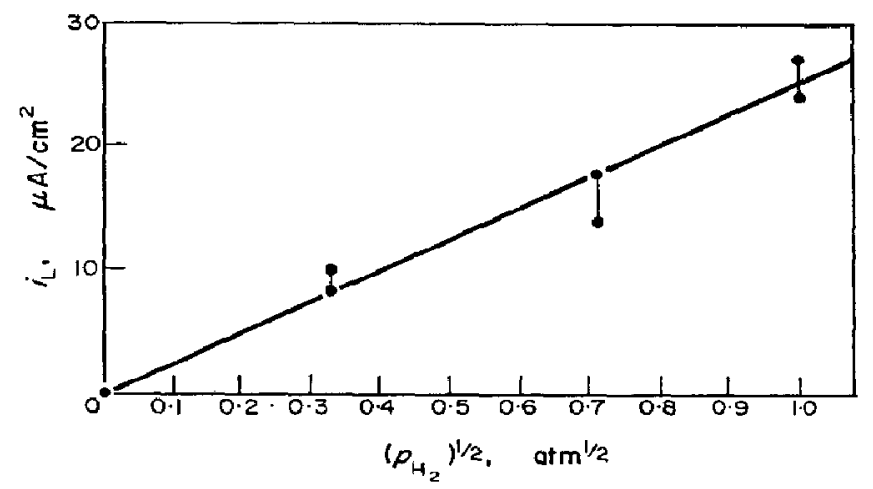

FIG. 10. Dependence of the anodic limiting $c d$ on the square root of the hydrogen partial pressure. 
TABLE 3. ANODIC APPARENT LIMTTING cdS FOR DIFFERENT THICKNESS OF POROUS GRAPHITE ELECTRODES AT $251^{\circ} \mathrm{C}$

\begin{tabular}{cr}
\hline $\begin{array}{c}\text { Thickness } \\
\mathrm{mm}\end{array}$ & \multicolumn{1}{c}{$\begin{array}{c}i_{\mathrm{L}} \\
\mu \mathrm{A} / \mathrm{cm}^{2}\end{array}$} \\
\hline $2 \cdot 60$ & $11 \cdot 6-16 \cdot 8$ \\
$4 \cdot 03$ & $9 \cdot 5-11 \cdot 6$ \\
6.29 & $14 \cdot 1-17 \cdot 8$ \\
\hline
\end{tabular}

\section{Anodic potentiostatic $\mathrm{E} / \mathrm{i}$ curves}

When a potentiostatic anodic run was attempted in the overvoltage range from 0.010 to $0.200 \mathrm{~V}$, no steady current could be obtained; the cd approached zero after quite a long time. The effect was somewhat similar to that found during the establishment of a passive state on a metallic electrode.

\section{Contact angles}

The contact angles were determined from the sequence of pictures obtained from the molten sample on the graphite plate under hydrogen pressure. The main conclusion is that the melt wets the graphite in the presence of hydrogen, since the contact angle after about $10 \mathrm{~min}$ of salt melting was $50 \pm 5^{\circ}$. Nevertheless, about $30 \mathrm{~min}$ after melting the salt, as the bead of melt offers a relative high area for water elimination, the amount of pyrosulphate formed becomes so high that the melting point of the mixture increases beyond the temperature selected for the experiment, causing the solidification of the sample. However, due both to the small amount of sample used in the experiments and to the influence of products yielded by the thermal decomposition of the salt during the measurement, these results should only be considered of qualitative interest.

\section{DISCUSSION}

\section{Probable mechanism of the cathodic reaction}

The kinetics and mechanism of the hydrogen-evolution reaction have been dealt with in numerous papers, either in aqueous or non-aqueous solvents, as well as in molten salts. The postulated mechanisms consist of a scheme of consecutive reactions where the initial electron-transfer step is followed either by a hydrogen-adatom-plushydrogen-ion-discharge step or by a hydrogen-adatom-combination reaction on the electrode surface. Any of these partial reactions may be the rate-controlling step, depending on the nature of the electrochemical system.

Usually the mechanistic diagnostic criteria applied to aqueous as well as nonaqueous systems cannot be straightforwardly extended to ionic molten systems as the possibilities of getting reaction orders, by changing either hydrogen-ion concentration or water content, are very restricted. Therefore for ionic melts attention has to be focussed on the Tafel slopes, the kinetic parameters derived from non-steady measurements, the possible degree of surface coverage and the study of the reverse electrode process. Hence to attempt the elucidation of the mechanism of the electrochemical evolution of hydrogen on graphite let us firstly check the experimental Tafel slopes with those theoretically derived from the various possible reaction mechanisms, assuming 
that different adsorption isotherms prevail for the hydrogen adatom. Let us write the possible reaction steps as follows:

$$
\begin{aligned}
\left(\mathrm{H}^{+}\right)_{\text {melt }}+\mathrm{G}+\mathrm{e} & =(\mathrm{H}) \mathrm{G} \\
(\mathrm{H}) \mathrm{G}+\left(\mathrm{H}^{+}\right)_{\text {melt }}+\mathrm{e} & =\mathrm{H}_{\mathbf{2}}+\mathrm{G} \\
(\mathrm{H}) \mathrm{G}+(\mathrm{H}) \mathrm{G} & =\mathbf{H}_{\mathbf{2}}+\mathbf{2 G} .
\end{aligned}
$$

G means a particular site on the graphite surface and parentheses indicate species in an adsorbed state.

The theoretical Tafel slopes predicted for the possible reaction mechanisms based upon reactions (Ic), (IIc) and (IIIc) are given elsewhere ${ }^{14.15}$ and for continuity in this

\begin{tabular}{|c|c|c|c|c|c|}
\hline & \multirow{2}{*}{$\begin{array}{c}\begin{array}{c}\text { Stoichiometric } \\
\text { number }\end{array} \\
v\end{array}$} & \multicolumn{2}{|c|}{$\begin{array}{l}\text { Langmuir adsorption } \\
\theta \rightarrow 0 \\
\theta \rightarrow 1\end{array}$} & \multicolumn{2}{|c|}{$\begin{array}{c}\text { Temkin adsorption } \\
\text { Non-activated Activated }\end{array}$} \\
\hline & & $b_{\mathrm{T}}$ & $b_{\mathrm{T}}$ & $b_{\mathrm{T}}$ & $b_{T}$ \\
\hline Slow (Ic), fast (IIIc) & 2 & $2 R T / F$ & $2 R T / F$ & $2 R T / F$ & $2 R T / F$ \\
\hline Slow (Ic), fast (IIc) & 1 & $2 R T / F$ & $2 R T / 3 F$ & $2 R T / F$ & $R T / F$ \\
\hline Slow (IIIc), fast (Ic) & 1 & $R T / 2 F$ & $\infty$ & $R T / 2 F$ & $R T / F$ \\
\hline Slow (IIc), fast (Ic) & 1 & $2 R T / 3 F$ & $2 R T / F$ & $2 R T / 3 F$ & $R T / F$ \\
\hline
\end{tabular}
discussion have been summarized in Table 4.

TABle 4. Kinetic Derivatives For rds OF CATHOdic REACTION

The cathodic Tafel slope lies close to $R T / F$ both in dense as well as porous graphite, over the whole range of temperature investigated. Furthermore, this Tafel slope can be considered reliable as the cathodic process exhibits no hysteresis effect in the whole current range covered by experiments. The slope is related, as deduced from Table 4, only to three possible reaction mechanisms involving a Temkin-type adsorption for the hydrogen adatoms. One way to arrive now at a more definite conclusion about the likely mechanism of the cathodic process is to analyse the kinetic parameters obtained from the cathodic overvoltage decay. The decay slope, which coincides for both the dense and the porous graphite electrodes, is always lower than the Tafel slope. This fact can be explained if the electrode pseudocapacitance associated to the electrode reaction is potential-dependent according to an expression which in the limiting cases is given by $C_{8}=C_{0} \exp \left( \pm \eta / b^{\prime}\right)$. For this case, the experimental decay slope is

$$
b_{\mathrm{d}}=\frac{\mathrm{d} \eta}{\mathrm{d}\left[\ln \left(t+t^{\prime}\right)\right]}=\frac{1}{1 / b_{\mathrm{T}} \pm 1 / b^{\prime}},
$$

where $\eta$ is the electrode overvoltage, $t^{\prime}$ a time defined in the $\eta / \log t$ plot and $b_{\mathrm{T}}$ the mechanistically significant Tafel slope. Therefore the decay slope will be numerically smaller than the Tafel slope if the electrode pseudocapacitance decreases as overvoltage increases, as occurs when the surface coverage degree, $\theta$, is larger than 0.5 , and vice versa when the electrode pseudocapacitance increases with potential, that is when $\theta<0.5$. As there is an adsorption pseudocapacitance it is quite unlikely that step (Ic) may become rate-determining. The pseudocapacitances, particularly those obtained with the porous graphite electrode, decrease as potential increases, suggesting that under the present circumstances Temkin conditions actually prevail, 
involving a degree of surface coverage larger than 0.5 . Therefore, the only possibilities left are either reaction (IIc) or reaction (IIIc) as rate-determining in an activated adsorption process. Both possibilities involve a stoichiometric number of one, in coincidence with the experimental value. Unfortunately in this case stoichiometric number does not yield an unambiguous definition of the reaction mechanism. These possibilities have been already discussed for gold and palladium electrodes for the same electrode processes. ${ }^{16.17}$

From the kinetic point of view no particular attention is paid to the tendency to approach a cathodic limiting cd at high cathodic overvoltage, because in this region, due to the high cd, bubble formation takes place and the definition of the actual electrode area is quite uncertain.

\section{The activation energy of the cathodic process}

One surprising result of the present work was the large discrepancy observed in the experimental activation energies for the cathodic process obtained with dense graphite and with porous graphite. For the former electrode $\left(\Delta H^{*}\right)_{\mathrm{s}}=28.7 \mathrm{kcal} / \mathrm{mole}{ }^{9.10}$ and for the latter $\left(\Delta H^{*}\right)_{\mathrm{c}}=11.9 \mathrm{kcal} / \mathrm{mole}$. In spite of this difference the Tafel and decay slopes indicate that the same kinetics holds for both graphite electrodes. Therefore the difference of activation energies must be assigned principally to some cause not directly related to the actual mechanism of the electrode process.

It has been observed that the electrode differential capacitances for dense graphite change quite markedly with temperature and for porous graphite they are practically independent of temperature. A possible explanation of these facts lies in a change of the actual electrode area. This might be caused by surface oxidation, or a change of electrode wetting, which are independent of the kind of graphite electrode and consequently should equally affect both experimental results. As this is not the case, it is more reasonable to explain the above-mentioned effect by supposing that the porous electrodes used in the present case approach a constant area because of the levelling effect of gas bubbles coming through the porous disk, which may mask any of the formerly mentioned effects. But if one considers the temperature change of the differential electrode pseudocapacitance for dense graphite at $0.130 \mathrm{~V}$ overpotential, $C_{\mathrm{e}}=$ $0.97 \times 10^{5} \mu \mathrm{F} / \mathrm{cm}^{2}$ at $262^{\circ} \mathrm{C}$ and $C_{e}=1.62 \times 10^{5} \mu F / \mathrm{cm}^{2}$ at $278^{\circ} \mathrm{C}$, as indicating a change of real area with temperature, one obtains a normalizing factor of 1.66 to apply to the apparent exchange cd at the dense graphite electrode. If the so-corrected apparent exchange cds are plotted according to an Arrhenius equation (Fig. 11), the resulting experimental activation energy is $11.8 \mathrm{kcal} / \mathrm{mole}$ at zero overvoltage, in complete agreement with the result reported for porous graphite.

The adsorption of hydrogen gas on graphite at a solid/gas interface yields an adsorption energy of $45 \mathrm{kcal} / \mathrm{mole}$ and the activation energy for the adsorption process is comprised between 22 and $34 \mathrm{kcal} / \mathrm{mole}$ in the temperature range from 418 to $733^{\circ} \mathrm{C} . .^{18}$ These figures however cannot be directly used to interpret the experimental activation energy of the electrochemical process, since the experimental conditions prevailing in the adsorption experiments are different from those of the electrochemical run, because of the participation of ionic species in the latter. It is more reasonable, although not strictly valid, to compare the experimental figure with the values obtained by Kita and Nomura for the case of the hydrogen electrode on nickel. ${ }^{19}$ The experimental figure for this case, $15.7 \mathrm{kcal} / \mathrm{mole}$, was explained on the 


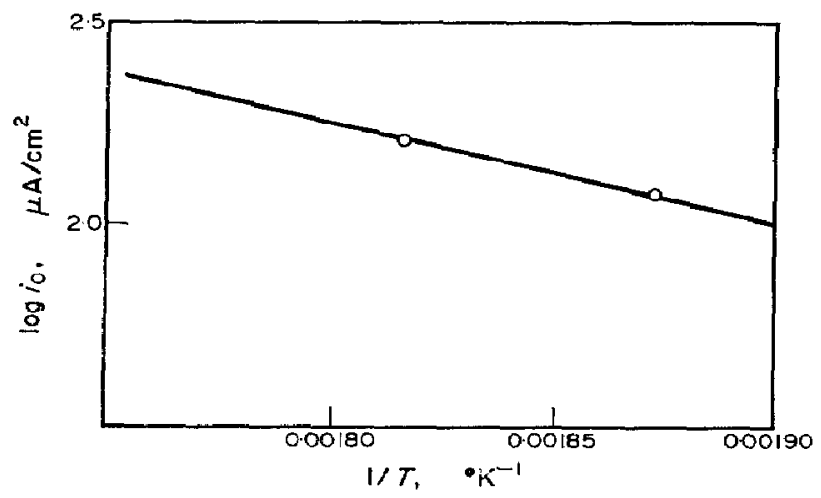

FIG. 11. Arrhenius plot for dense graphite cathodes after correction for the surface area change.

basis that the combination of adatoms is rate-determining with an intermediate degree of surface coverage. This result lies close to the experimental figure obtained for the reaction on graphite in the bisulphate melt.

\section{Probable mechanisms of the anodic reaction}

For the electrochemical oxidation of hydrogen on graphite, those mechanisms proposed for the reaction on platinum ${ }^{1,5}$ are in principle not considered, as no onehalf dependence of the anodic cd on hydrogen gas pressure is derived from them. Likcwisc, under steady-state conditions, the absorption of hydrogen on graphite probably has a minor importance in the kinetics of the reaction. However, as in the case of platinum electrodes, either a pre-oxidation of the electrode or the occurrence of the anodic reaction in the vicinity of the potential for the oxidation of the graphite surface might be of importance.

To deal with the mechanistic interpretation of the electrochemical dissolution of hydrogen on graphite in bisulphate melts, let us consider the different reaction pathways, which very likcly must comprise the reverse of those reactions described for the cathodic process.

Let us first consider a simple reaction scheme starting either with reaction (Ia) or (IIa):

followed by

$$
\begin{aligned}
2 \mathrm{G}+\mathrm{H}_{2} & =2 \mathrm{G}(\mathrm{H}), \\
\mathrm{G}+\mathrm{H}_{\mathbf{2}} & =\mathrm{G}(\mathrm{H})+\left(\mathrm{H}^{+}\right)_{\text {melt }}+\mathrm{e},
\end{aligned}
$$

$$
\mathrm{G}(\mathrm{H})=\left(\mathrm{H}^{+}\right)_{\text {melt }}+\mathrm{G}+\mathrm{e} .
$$

The theoretical parameters derived from the different mechanisms comprising either reaction (Ia), (IIa) or (IIIa) as rate-determining, under different isotherms, ${ }^{15}$ are compiled in Table 5. As seen in this table, if the anodic reaction involves the dissociation of a hydrogen molecule as the rate-determining step then at high positive potentials, an anodic limiting cd of kinetic nature should exist. If this should be the case, however, a first-order dependence of the reaction rate on hydrogen gas pressure would be expected. But the latter is not obeyed as the limiting current density depends on the square root of gas pressure. Then, reaction (Ia) should in principle be discarded as rate-determining. For the same reason a convective diffusion kinetic control is also quite unlikely. Nevertheless it is possible to estimate, for dense graphite electrodes, the concentration of hydrogen gas at the electrode surface, $c_{\mathbf{B}_{2}}{ }^{5}$, by assuming that the 
TABle 5. KINETIC Derivatives for RdS OF ANODIC Reaction

\begin{tabular}{|c|c|c|c|c|c|}
\hline & \multirow{2}{*}{$\begin{array}{c}\begin{array}{c}\text { Stoichiometric } \\
\text { number }\end{array} \\
v\end{array}$} & \multicolumn{2}{|c|}{ Langmuir adsorption } & \multicolumn{2}{|c|}{$\begin{array}{c}\text { Temkin adsorption } \\
\text { Non-activated Activated }\end{array}$} \\
\hline & & $b_{\mathrm{T}}$ & $b_{\mathbf{T}}$ & $b_{\mathbf{T}}$ & $b_{\mathbf{T}}$ \\
\hline Slow(IIIa), fast(Ia) & 2 & $2 R T / F$ & $2 R T / F$ & $2 R T / F$ & $2 R T / F$ \\
\hline Slow(IIIa), fast(IIa) & 1 & $2 R T / 3 F$ & $2 R T / F$ & $2 R T / 3 F$ & $R T / F$ \\
\hline Slow(Ia), fast(IIIa) & 1 & $\infty$ & $R T / 2 F$ & $\infty$ & $R T / F$ \\
\hline Slow(IIa), fast(IIIa) & 1 & $2 R T / F$ & $2 R T / 3 F$ & $2 R T / F$ & $R T / F$ \\
\hline
\end{tabular}

limiting anodic cd may correspond to a mass-transport process. For hydrogensaturated melt at one atmosphere pressure, the anodic limiting cd is $3 \times 10^{-5} \mathrm{~A} /$ $\mathrm{cm}^{2}$ at $240^{\circ} \mathrm{C}$; then the surface concentration is given to a first approximation by

$$
c_{\mathrm{H}_{2}}{ }^{s}=c_{\mathrm{H}_{2}}{ }^{o}-\frac{i_{\mathrm{d}} \delta}{z F D_{\mathrm{H}_{2}}},
$$

where $c_{\mathrm{H}_{2}}{ }^{\circ}$ is the hydrogen gas concentration in the bulk of the melt (taken as $10^{-6}$ $\left.\mathrm{mol} / \mathrm{cm}^{3}\right), z$ the number of charges per mole of hydrogen, $F$ the Faraday, $D_{\mathrm{H}_{\mathbf{z}}}$ the diffusion coefficient of the hydrogen molecule (taken as $10^{-5} \mathrm{~cm}^{2} / \mathrm{s}$ ) and $\delta$ the average thickness of the diffusion layer (about $10^{-3} \mathrm{~cm}$ ). The estimated value for $c_{\mathrm{H}_{\mathrm{a}}}{ }^{\mathrm{s}}$ is $0.98 \times$ $10^{-6} \mathrm{~mole} / \mathrm{cm}^{3}$, a figure very close to $c_{\mathrm{H}_{2}}{ }^{\circ}$. Therefore any convective diffusion contribution should be less than 2 per cent of the measured effect. Another result supporting this conclusion for porous graphite electrodes is the absence of any appreciable effect of bubbling rate on the limiting anodic cd. Finally, any appreciable masstransport contribution can be neglected on the basis of the magnitude of the limiting anodic cd obtained with both graphite electrodes, and the different diffusional paths involved.

We now consider the reaction mechanisms yielding a one-half order dependence with respect to hydrogen gas pressure. The simplest reaction scheme can be easily conceived on the basis of steps (Ia) followed by (IIIa). Various possibilities are involved for this set of reactions.

Mechanism I. Let us first consider a sort of electrocatalysis mechanism without adsorption control and assume that reaction (Ia) in both directions is sufficiently rapid for equilibrium to exist between hydrogen atoms and molecular hydrogen. Then

$$
\left(c_{\mathrm{H}}^{\mathrm{B}}\right)^{2}=K_{\mathrm{I}}\left(p_{\mathrm{H}_{\mathrm{z}}}^{\mathrm{B}}\right) \text {, }
$$

where $c_{\mathrm{H}}{ }^{8}$ is the surface concentration of hydrogen atoms, $p_{\mathrm{H}_{2}}{ }^{8}$ the hydrogen gas pressure at the electrode surface and $K_{\mathrm{I}}$ includes the equilibrium constant of reaction (Ia), the corresponding conversion factors between surface concentration and pressure at the surface, the activity of the graphite surface (assumed constant) and the corresponding activity coefficients ratio. If the dissolution process is determined by the rate of the reaction (IIIa), the cd due to the ionization reaction, $i_{a}$, is

$$
i_{\mathrm{a}}=z F k_{\mathrm{IIIa}}\left(c_{\mathrm{H}^{8}}\right) \exp \left(\frac{\alpha_{\mathrm{a}} \eta F}{R T}\right)=z F k_{\mathrm{IIIa}}\left[K_{\mathrm{I}}\left(p_{\mathrm{H}_{\mathrm{a}}}^{\mathrm{s}}\right)\right]^{1 / 2} \exp \left(\frac{\alpha_{\mathrm{a}} \eta F}{R T}\right),
$$

where $k_{\text {IITa }}$ is the rate constant of step (IIIa) in the forward direction and $\alpha_{\mathrm{a}}$ the transfer coefficient assisting the reaction in the anodic direction. Equation (4) yields, 
at a constant overvoltage $\eta$, a one-half dependence of $i_{\mathrm{a}}$ on $\mathrm{p}_{\mathrm{H}_{\mathrm{a}}}{ }^{\mathrm{s}}$, but no anodic limiting cd results from this reaction pathway, except by a compensation of terms in the rate equation. That is when $C_{\mathrm{H}}^{\mathrm{B}} \rightarrow 0$, due to any simultaneous hindrance for the occurrence of hydrogen atoms on the graphite surface, $\eta$ would approach infinity and consequently $i_{\mathrm{a}}$ would approach a limiting value.

Mechanism II. On the basis of reactions (Ia) and (IIIa) let us consider now an adsorption kinetics with a Langmuir adsorption isotherm. According to reaction (Ia), from the equations for the rate of adsorption and desorption, the degree of surface coverage by hydrogen adatoms, $\theta_{\mathrm{H}}$,

$$
\theta_{\mathrm{H}}=\frac{\left(\frac{k_{\mathrm{I}}}{k_{-\mathrm{I}}}\right)^{1 / 2}\left(p_{\mathrm{H}_{\mathrm{z}}}^{\mathrm{g}}\right)^{1 / 2}}{1+\left(\frac{k_{\mathrm{I}}}{k_{-\mathrm{I}}}\right)^{1 / 2}\left(p_{\mathrm{H}_{2}}^{\mathrm{g}}\right)^{1 / 2}} .
$$

If the rate of hydrogen dissolution is proportional to the total surface concentration of hydrogen ad atoms, $c_{\mathrm{H}}$,

$$
i_{\mathrm{a}}=z F k_{\mathrm{III} a_{\mathrm{H}}} \exp \left(\frac{\alpha_{\mathrm{a}} \eta F}{R T}\right)=\frac{z F k_{\mathrm{IIIa}}\left(\frac{k_{\mathrm{I}}}{k_{-\mathrm{I}}}\right)^{1 / 2} c_{\mathrm{s}}\left(p_{\mathrm{H}_{2}}^{\mathrm{g}}\right)^{1 / 2}}{1+\left(\frac{k_{\mathrm{I}}}{k_{-\mathrm{I}}}\right)^{1 / 2}\left(p_{\mathrm{H}_{2}}^{\mathrm{g}}\right)^{1 / 2}} \exp \left(\frac{\alpha_{\mathrm{a}} \eta F}{R T}\right) .
$$

If there is no hydrogen pressure gradient at the interface, $p_{\mathrm{H}_{2}}{ }^{8} \rightarrow p_{\mathrm{H}_{2}}{ }^{\circ}$, where $p_{\mathrm{H}_{2}}{ }^{\circ}$ is the saturation pressure of hydrogen gas in the bulk of the melt. For the establishment of a kinetic limiting current, $c_{\mathrm{H}}$ must approach zero and the experimental term should approach infinity. Then, the kinetic limiting cd would depend on the square root of hydrogen gas in the bulk of the melt if $\left[\left(k_{\mathrm{I}} / k_{-\mathrm{r}}\right) \boldsymbol{p}_{\mathrm{H}_{\mathbf{2}}}{ }^{\circ}\right]^{1 / 2} \ll 1$. This interpretation for the anodic reaction does not conjugate with the likely reaction mechanism postulated for the cathodic formation of hydrogen, if the processes are complementary. The present results, however, suggest that the anodic and cathodic reactions are not complementary from the standpoint of their reaction mechanisms.

Mechanism III. The one-half reaction order with respect to the hydrogen gas pressure can also be derived from two main reaction mechanisms involving the participation of at least two types of active centres on the electrode surface. The first mechanism, which has been postulated particularly for platinum electrodes in aqueous solutions, ${ }^{20}$ is expressed by

$$
\begin{aligned}
2 \mathrm{G}_{1}+\mathrm{H}_{2} & =(\mathrm{H}) \mathrm{G}_{1}+\left(\mathrm{H} \mathrm{G}_{1},\right. \\
\mathrm{G}_{2}+\mathrm{G}_{1}(\mathrm{H}) & =\mathrm{G}_{2}(\mathrm{H})+\mathrm{G}_{1}, \\
\mathrm{G}_{2}(\mathrm{H}) & =\left(\mathrm{H}^{+}\right)_{\text {melt }}+\mathrm{G}_{2}+\mathrm{e} .
\end{aligned}
$$

It is asserted that suitable adsorption sites on graphite cover a range of energies; the discharge of hydrogen ions occurs preferentially at sites of higher adsorption energy, while the ionization process takes place at lower energy sites. Hydrogen adatoms can redistribute by surface migration between the high and low energy sites, types 1 and 2 .

The existence of weak and strongly bonded adatoms and their rapid interconvertion as indicated by ( $\mathrm{Va})$, is fairly well established at least for the case of the 
platinum metals, ${ }^{21-24}$ and the degree of surface coverage by weakly bonded adatoms is usually taken to be much lower than that of the strongly bonded. ${ }^{25}$

If it is assumed that reactions (IVa) and (Va) are sufficiently rapid for equilibrium to be established between adatoms and hydrogen molecules, then equation (3) is valid, and this mechanism yields a rate equation of the same form as (4), so that the same conclusion applies.

Another possibility exists if there is a potential where the rates of step ( Va) and (VIa) are equal. Then, at low overvoltages, reaction (VIa) is rate-controlling and the rate of the reaction is given by an expression formally equal to those mentioned in mechanisms I and II. However, as the potential becomes more positive, the rate of step (VIa) increases exponentially until its rate exceeds the rate of step (Va) so that the latter becomes rate-determining. Under these circumstances

$$
i_{\mathrm{a}}=z F k_{\mathrm{Va}} c_{\mathrm{G}_{2}} c_{\mathrm{H}} \text {, }
$$

where $c_{\mathrm{G}_{2}}$ and $c_{H}$ are the concentration of free type 2 active sites and the concentration of type 1 active sites filled with bydrogen adatoms, respectively. Taking into account that step (IVa) is in quasi-equilibrium, from (5) with a Langmuir adsorption isotherm if $\left[\left(k_{\mathrm{I}} / k_{-1}\right)\left(p_{\mathrm{H}_{\mathrm{z}}}^{\mathrm{s}}\right)\right]^{1 / 2} \ll 1$, (7) leads to

$$
i_{\mathrm{a}}=z F k_{\mathrm{Va}_{\mathrm{a}}} c_{\mathrm{G}_{\mathbf{2}}}\left(K_{\mathrm{I}}^{\prime} p_{\mathrm{H}_{2}}^{\mathrm{g}}\right)^{1 / 2} \text {, }
$$

giving to $i_{\mathrm{a}}$ a one-half power dependence on hydrogen pressure and independence of potential.

The two postulated possibilities dealt with in this mechanism, although they apparently satisfy the galvanostatic cd/potential curves, do not take into account the hysteresis effect noticed in the potentiostatic as well as galvanostatic experiments. It may be explained if the concentration $c_{\mathrm{G}_{2}}$ diminishes as a function of time because of thermal oxidation.

Mechanism IV. Let us assume that hydrogen oxidation on graphite takes place by the sequence of reactions (IVa) to (VIa) and further consider that an intermediate degree of surface coverage by hydrogen adatoms exists. For low anodic overvoltages this is a reasonable assumption derived from the dependence of the electrode capacitance on electrode potential occurring in the cathodic region. The fact that graphite adsorbs hydrogen is well established independently of any electrochemical study. Thus, hydrogen adsorption on graphite at high temperatures takes place as a partial process during the chemical reaction between hydrogen and graphite. ${ }^{26-28}$ At $300^{\circ} \mathrm{C}$ hydrogen adsorption on freshly ground graphite surfaces is completely irreversiblc and active centres are located on the prismatic surfaces. ${ }^{29}$

As hydrogen adsorption occurs, let us add the assumption that the number of active sites on graphite for hydrogen adsorption, diminish because of the oxidation of the electrode surface due to the oxidizing conditions prevailing at the graphite anode and neglect any difference of sites 1 and 2 for hydrogen atom adsorption. This means the occurrence of a reaction such as

$$
\mathrm{G}^{*}+(\mathrm{O}) \mathrm{X}=\mathrm{G}^{*}(\mathrm{O})+\mathrm{X},
$$

which blocks active centres. (O)X is any oxygen containing species able to react on the graphite surface.

There are many evidences for oxidation reactions such as (VIIa). Thus, anodic films on pyrolitic graphite which apparently reduce irreversibly have been observed. ${ }^{30}$ 
These oxidation processes may involve different states of the peripheral carbon atoms $^{31}$ and are related in the case of active carbons to the formation of paramagnetic centres analogous to those observed on carbon blacks. ${ }^{32}$ Therefore, to admit the competition of hydrogen and oxygen atoms for graphite active centres, as reactions (IVa), (Va) and (VIIa) imply, means that on the electrode surface chemisorbed oxygen as well as hydrogen can always be found. Actually this has been observed for graphite electrodes at room temperature ${ }^{33-35}$ and oxygen in these circumstances can determine the electrode potential of graphite. ${ }^{8}$

On the basis of previous ideas, let us postulate that reaction (VIa) is ratedetermining, so the rate of hydrogen ionization, in terms of cd, is

$$
i_{\mathrm{a}}=z F k_{\mathrm{VIa}} \theta_{\mathrm{II}} \exp \left(\frac{\alpha_{\mathrm{a}} \eta F}{R T}\right) .
$$

If reaction (VIIa) blocks the active centres, at least three different portions of the surface should be distinguished so that the degrees of surface coverage are related as follows,

$$
\theta_{\mathrm{H}}+\theta_{\mathrm{o}}+\theta_{\mathrm{F}}=1 \text {, }
$$

where $\theta_{\mathrm{H}}, \theta_{\mathrm{O}}$ and $\theta_{\mathrm{F}}$ correspond respectively to the degree of surface coverage by hydrogen adatoms, to surface coverage by oxygen and to the free graphite active centres. If reaction (IVa) is in quasi-equilibirum

$$
K_{\mathrm{IVa}}^{\prime}=\frac{\left(\frac{c_{\mathrm{H}}}{c_{\mathrm{s}}}\right)^{2}}{\frac{\left[c_{\mathrm{s}}-\left(c_{\mathrm{H}}+c_{\mathrm{o}}\right)\right]^{2}}{c_{\mathrm{s}}{ }^{2}} \cdot p_{\mathrm{H}_{\mathrm{z}}}{ }^{\mathrm{s}}},
$$

where $c_{\mathrm{H}}, c_{\mathrm{O}}$ and $c_{\mathrm{s}}$ correspond respectively to the surface concentration of hydrogen adatoms, the concentration of oxidized sites and the total surface concentration of graphite active sites. After assuming that the degree of surface coverage by hydrogen adatoms, at anodic overvoltages, is much lower than the degree of coverage of graphite by oxygen, the degree of surface coverage by hydrogen adatoms is

$$
\theta_{\mathrm{H}}=\left(K_{\mathrm{IVa}}^{\prime} p_{\mathbf{H}_{2}}^{\mathrm{g}}\right)^{1 / 2}\left(1-\theta_{\mathrm{O}}\right) \text {. }
$$

Then, by replacing $\theta_{\mathrm{H}}$ in (9) by its expression given by (12), the following rate equation results,

$$
i_{\mathrm{a}}=z F k_{\mathrm{\nabla Ia}}\left(K_{\mathrm{VIa}}^{\prime}\right)^{1 / 2}\left(1-\theta_{\mathrm{O}}\right) p_{\mathrm{H}_{\mathrm{a}}}^{1 / 2} \exp \left(\frac{\alpha_{\mathrm{a}} \eta F}{R T}\right),
$$

where $p_{\mathrm{H}_{2}}{ }^{\mathrm{s}} \approx p_{\mathrm{H}_{2}}{ }^{\circ}=p_{\mathrm{H}_{2}}$. According to (13), if $\theta_{\mathrm{O}}$ approaches unity two different situations arise, corresponding either to potentiostatic or galvanostatic conditions. (i) At constant overvoltage (potentiostatic runs) the cd will become smaller as the number of available sites for the hydrogen oxidation is reduced. (ii) At constant current (galvanostatic runs), the anodic overvoltage will increase, as it corresponds to a limiting cd and the latter will depend on the square root of the hydrogen gas pressure.

The increase of $\theta_{\mathrm{O}}$ at anodic potential is related to the anodic oxidation of graphite which is known to occur in molten electrolytes, ${ }^{36,37}$ as well as in sulphuric acid at 
$25^{\circ} \mathrm{C.}^{38}$ The question is, how $0_{\mathrm{o}}$ changes with time at a constant potential, and with potential at infinite time. The present experiments give no answer to the former question except that in the limiting cd region, at constant potential, the current decay is rather slow, so that in a rapid anodic potential sweep the limiting current region is overlooked and the region of net anodic oxidation of graphite is reached. The latter, as already known, corresponds to a Tafel line with a slope $R T / F .{ }^{37}$ However, some idea about the effect of potential on the state of the surface is gained from the voltammetric $E / I$ curves described in the first part of this work, ${ }^{10}$ where two anodic and two cathodic peaks were detected. The small oxidation peak located at $0 \cdot 280 \mathrm{~V}$ may correspond either to hydrogen oxidation or oxygen adsorption on the graphite surface and the second oxidation peak either to oxygen adsorption or to the formation of graphite bisulphate lamellar compound, ${ }^{39}$ prior to $\mathrm{CO}$ and $\mathrm{CO}_{2}$ formation. The hysteresis observed on the $E / I$ voltammetric runs suggests that some oxide is left without reduction after each cycle and that the electrochemical process is irreversible.

The experimental results are clear evidence of the surface oxidation of graphite at positive potentials as low as those corresponding to the hydrogen ionization reaction, as indicated for instance, by the hysteresis and discontinuity of the $E / I$ curves run by changing the potential upwards and downwards in the neighbourhood of the rest potential of the graphite electrode (Fig. 6). These results also agree with the probable mechanism postulated for the anodic oxidation of graphite in bisulphate melts. ${ }^{37}$

This interpretation of the anodic reaction is also supported by the fact that passivity is not restricted only to the anodic metal dissolution but also seems to occur in the anodic oxidation of hydrogen on platinum, with normal sulphuric acid solutions. ${ }^{7}$ In this case results are akin to those reported in the present work, including their time dependence. The difference between galvanostatic and potentiostatic $E / I$ curves is well known for those electrochemical systems where passivity may occur; the former curve usually exhibits a large hysteresis effect when retracted by decreasing the electrode potential.40

We conclude that the anodic and cathodic reactions on graphite in the present case occur on different electrode surface sites. The switching from the cathodic to the anodic mechanism can be assigned to a relative rate change of partial steps due to the oxidized graphite surface.

Acknowledgements-This work was supported by the U.S.A.F. Grant AFOSR-69-1780. One of the authors (E. J. B.) is indebted to the Consejo Nacional de Investigaciones Cientificas y Técnicas of Argentina for the fellowship granted.

\section{REFERENCES}

1. T. C. Franklin and S. L. CoOKe, JR., J. electrochem. Soc. 107, 556 (1960).

2. D. T. SAWYER and E. T. SEO, J. electroanal. Chem. 5, 23 (1963).

3. G. P. Lewis and P. RuetschI, J. phys. Chem. 67, 65 (1963).

4. A. FRUMKIN, in Adwances in Electrochemistry and Electrochemical Engineering, ed. P. DeLAHAY and C. W. ToBIAS, Vol. 3, p. 287. Interscience, New York (1963).

5. M. P. Makowski, E. Heitz and E. Yeager, J. electrochem. Soc. 113, 204 (1966).

6. G. R. BopP, P. MAsON and D. M. STONEHART, Electrochem. Techn. 4, 416 (1966).

7. Y. M. KoLOIYRKIN, Z. Elektrochem. 62, 664 (1958).

8. M. I. Gillibrand, K. Graham and G. R. LomaX, Trans. Faraday Soc. 62, 2895 (1966).

9. E. Balskus, J. J. Podesta and A. J. Arví, Electrochim. Acta 16, 1663 (1971).

10. E. Balskus, J. J. Podesté and A. J. ARvia, Electrochim. Acta, 15, 1557 (1970).

11. S. Senderoff and G. W. Mellors, Rev. Sci. Instrum. 29, 151 (1958).

12. H. A. Videla and A. J. ARvfA, Electrochim. Acta 10, 21 (1965).

13. A. J. Arvía, A. J. Calandra and H. A. Videla, Electrochim. Acta 10, 33 (1965). 
14. B. E. Conway, Theory and Principles of Electrode Processes. Ronald Press, New York (1965).

15. W. E. TriacA, C. Solomons and J. O'M. Bockris, Electrochim. Acta 13, 1949 (1968).

16. A. J. Arvta, F. de Vega and H. A. Videla, Electrochim. Acta 13, 581 (1968).

17. A. J. Arvita, A. J. Calandra and H. A. Videla, Electrachim. Acta 14, 25 (1969).

18. R. M. BARRER, J. chem. Soc., Lond. 1256 (1936).

19. H. KITA and O. Nomura, J. Res. Inst. Cat. Hokkaido Univ. 13, 107 (1965).

20. G. J. Hills and D. G. J. Ives, J. chem. Soc., Lond. 305 (1951).

21. A. EuCKEN and B. Weblus, $Z$. Elektrochem. 55, 114 (1951).

22. E. WICKE and B. WeBlus, Z. Elektrochem. 56, 169 (1952).

23. M. BreITER and C. KNORR, $Z$. Elektrochem. 59, 153 (1955).

24. M. BretTer and C. KNORR, Z. Elektrochem. 59, 681 (1955).

25. E. Yeager, 20th CITCE Meeting, Strasbourg, Extended Abstr. p. 3 (1969).

26. J. D. Blackwood, Australian J. Chem. 12, 15 (1959).

27. C. W. ZIELKE and E. GoRIN, Ind. eng. Chem. 47, 820 (1955).

28. E. A. Guldransen, K. F. Andrew and F. Bassart, J. electrochem. Soc. 112, 49 (1965).

29. G. B. Demidovitch, V. F. Kiselev, N. N. Lejnev and O. V. Nikitina, J. Chim. phys. 65, 1072 (1968).

30. G. Mamantov, D. B. Freeman, F. J. Miller and H. E. Zrtrel, J. electroanal. Chem. 9, 305 (1965).

31. C. A. Coulson, Proc. 4th Conf. on Carbon, p. 215 (1959).

32. M. F. Charlier, G. Kappel, N. Perol, A. Charlier and P. Tagle, J. Chim. phys. 66, 1158 (1969).

33. L. Rédey and N. Lohonyal, Abhand. Säch. Akad. Wissens. Leipzig 49, 97 (1968).

34. R. Nelson-Smith, Quart. Rev. 13, 287 (1959).

35. H. P. Boehm, E. DiehL, N. Heck and R. SAPPok, Angew. Chem. 76, 752 (1964).

36. A. J. Arvita and W. E. TriacA, Anal. Asoc. quim. arg. 56, 33 (1968).

37. A. J. Arvía, W. E. Triaca and H. A. Videla, Electrochim. Acta 15, 9 (1970).

38. R. FuJII and K. Matsuo, Tanso 53, 57 (1968).

39. A. R. Ubrelohde and F. A. LewIS, Graphite and its Crystal Compounds, p. 163. Oxford University Press, London (1960).

40. M. Brerter, Electrochemical Processes in Fuel Cells. Springer, Berlin (1969). 